\title{
PEMBUATAN WEBSITE TK AISYISAH BUSTANUL ATHFAL 16 (ABA) MALANG
}

\author{
M. Irfan ${ }^{1}$, Yoga Nur Fimansyah ${ }^{2}$, Nurhadi $^{3}$, Lailis Syafa'ah $^{4}$, Merinda Lestandy ${ }^{5^{*}}$ \\ ${ }^{1,2,3,4)}$ Program Studi Teknik Elektro, Fakultas Teknik, Universitas Muhammadiyah Malang \\ ${ }^{5}$ Program Studi D3 Teknologi Elektronika, Fakultas Teknik, Universitas Muhammadiyah Malang \\ email: merindalestandy@umm.ac.id
}

\begin{abstract}
Abstrak
TK ABA 16 Malang saat ini adalah belum memiliki fasilitas website dimana setiap terdapat informasi mengenai sekolah hanya ditampilkan di majalah dinding sekolah. Tetapi kegiatan tersebut dirasa kurang maksimal karena saat ini perkembangan teknologi informasi semakin cepat, maka semakin banyak bidang yang bergantung pada teknologi informasi digital, salah satunya yaitu Website. Website ini dibuat sebagai bahan pertimbangan dalam penyampaian informasi dan profil TK 'Aisyiyah Bustanul Athfal 16 Malang agar lebih dikenal dan dapat diakses dengan mudah oleh guru, wali murid dan pihak luar sekolah. Website TK ABA 16 Malang ini berisikan profil sekolah yang terdiri dari sejarah, visi misi, tujuan sasaran, sarana dan prasarana dan galeri. Data tersebut oleh TK ABA 16 Malang dipergunakan sebaik-baiknya untuk meningkatkan mutu sekolah dan penyampaian infomasi sekolah kepada semua pihak dengan cepat dan efisien. Website ini dibuat dengan program PHP dan database MySQL. Hasil dari pelaksanaan kegiatan ini yaitu berupa website www.tkaba16malang.com.
\end{abstract}

Kata Kunci: TK ABA 16 Malang, Sekolah, Website

\begin{abstract}
TK ABA 16 Malang currently does not have a website facility where any information about the school is only displayed on the school wall magazine. However, these activities are considered less than optimal because currently the development of information technology is getting faster, so there are more and more fields that depend on digital information technology, one of which is the website. This website was created as a material for consideration in delivering information and profiles of Kindergarten 'Aisyiyah Bustanul Athfal 16 Malang so that it is better known and can be accessed easily by teachers, guardians of students and parties outside the school. The website of TK ABA 16 Malang contains a school profile consisting of history, vision and mission, target goals, facilities and infrastructure and a gallery. The data is used by TK ABA 16 Malang as well as possible to improve school quality and convey school information to all parties quickly and efficiently. This website is created with PHP program and MySQL database. The result of the implementation of this activity is a website www.tkaba16malang.com.
\end{abstract}

Keywords: TK ABA 16 Malang, School, Website

\section{PENDAHULUAN}

Pesatnya perkembangan ilmu pengetahuan dan teknologi pada saat ini tidak dapat dipungkiri lagi. Kebutuhan yang mendesak dan semakin berharganya nilai waktu membuat banyak orang bekerja dengan cepat dan efektif sehingga mendapatkan hasil yang semaksimal mungkin(Ramadhani et al., 2013). Teknologi informasi dan komunikasi melahirkan berbagai media yang mampu memberikan informasi yang dapat diakses kapanpun dan dimanapun yaitu website. Website menjadi salah satu media yang sering dimanfaatkan oleh manusia baik untuk kepentingan pribadi maupun kepentingan institusi (Christian et al., 2018). Dalam dunia pendidikan informasi adalah bagian penting dari komponen pendidikan yang dituntut untuk didapatkan secara cepat, tepat dan mudah agar mendukung segala bentuk kegiatan pendidikan yang sedang dan akan berlangsung di instansi-instansi tertentu.

Pendidikan mempunyai peranan yang amat strategis untuk mempersiapkan generasi muda yang memiliki keberdayaan dan kecerdasan emosional yang tinggi dan menguasai megaskills yang mantap. Sejarah telah membuktikan bahwa kemajuan dan kejayaan suatu bangsa di dunia 
ditentukan oleh kualitas dan mutu dibidang pendidikan (Fauzi, 2019). Sekolah merupakan lembaga diberi wewenang untuk menyelenggarakan kegiatan belajar dan mengajar antara siswa dan guru. Sampai dengan saat ini sekolah masih diberikan kepercayaan oleh sebagian besar masyarakat untuk menjadi tempat bagi siswa untuk menuntut ilmu dan sebagai tempat proses mendewasakan anak-anak(Irawan et al., 2016).

Website sekolah sekarang ini sedang menjadi tren didunia pendidikan dan website sekolah mendapat perhatian (Simanjorang et al., 2017), tanggapan yang sangat bagus dari berbagai pihak baik dari tenaga kependidikan, wali murid dan juga masyarakat. Seiring perkembangannya juga, website sekolah ini dirasa diperlukan, menjadi added value/ nilai tambah citra sekolah juga sebagai sarana penyampai informasi sekolah seperti kegiatan, prestasi sekolah, jadwal penerimaan peserta didik baru, kontak sekolah dan banyak hal lainnya.

TK ABA 16 berdiri secara resmi pada tanggal 1 Januari 1971. Awalnya TK ABA 16 merupakan kepemilikan pribadi salah seorang tokoh Muhammadiyah Ranting Dinoyo yaitu $\mathrm{Hj}$. Fathkhurozi yang berlokasi di Jl. MT haryono Gang II No 517 Kota Malang. Kemudian TK ABA 16 diwaqafkan kepada kepemimpinan Aisyiyah yaitu Ibu Abdullah Hasyim. Beliau menjabat sebagai ketua Aisyiyah Ranting Dinoyo selama 1 periode (5 tahun). Kemudian pada periode ke 2 dijabat oleh Hj. Ikhsan sampai tahun 1984. Kepemimpinan TK ABA 16 Ranting Dinoyo periode ke 3 dijabat kembali oleh Abdullah Hasyim, setelah itu TK ABA 16 dipindahkan dan dibangun di Jl. Watu Gilang no. 43 Kota Malang. Kemudian pada tahun 2000, periode ke 4 dipimpin oleh Dra. Nurliani sampai tahun 2005. Periode ke 5 dipimpin oleh Asminingtyas, S.Pd sampai tahun 2010. Pada periode ke 6 dipimpin oleh Hj. Dra. Dwi Widariyati hingga sekarang. Nama TK ABA 16 merupakan TK dengan urutan ke 16 dari 34 TK ABA Se Kota Malang, dan yang bertanggung jawab atas TK ABA 16 adalah Pimpinan Aisyiyah Ranting Dinoyo.

Berdasarkan hasil diskusi tim pengusul dengan mitra, permasalahan TK ABA 16 Malang saat ini adalah belum memiliki fasilitas website dimana setiap terdapat informasi mengenai sekolah hanya ditampilkan di majalah dinding sekolah. Hal tersebut membuat TK ABA 16 Malang kurang dikenal masyarakat karena kurangnya fasilitas yang dimiliki oleh sekolah untuk menyampaikan informasi kepada masyarakat. Berdasarkan analisisa situasi yang kami lakukan, tim sepakat bersama mitra bahwa dalam program pengabdian oleh tim tahun ini adalah kegiatan pengabdian kepada masyarakat dengan membuat Website TK 'Aisyiyah Bustanul Athfal 16 Malang, dengan tujuan agar dapat dikenal oleh masyarakat dan dapat meningkatkan mutu sekolah serta penyampaian infomasi sekolah kepada semua pihak dengan cepat dan efisien. Selain itu dengan adanya web ini, mudah untuk diakses oleh guru, wali murid dan pihak luar sekolah.

\section{METODE}

Metode pengembangan sistem yang digunakan dalam pembuatan sistem ini adalah metode model air terjun atau yang sering disebut dengan istilah waterfall. Ada enam tahapan dalam model waterfall yaitu (1). System Engineering (2). Analysis (3). Design (4). Coding. (5). Testing (6). Maintenance. Berikut adalah gambaran dari metode System Engeneering, Analysis, Design, Coding, Testing, Maintenance dapat dilihat pada Gambar 1.

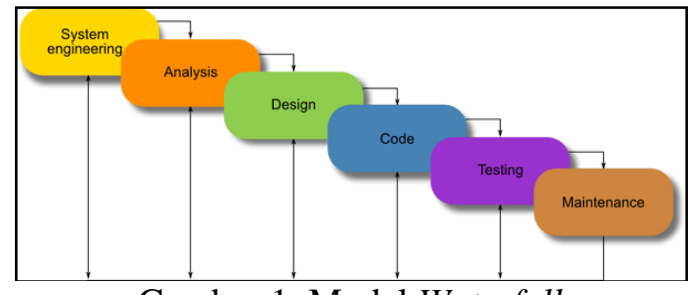

Gambar 1. Model Waterfall

Dari gambar diatas dapat dijelaskan menjadi beberapa bagian yaitu yang pertama System Engineering atau rekayasa sistem dan analisa merupakan pembentukan kebutuhan dari semua elemen sistem dan menganalisa kebutuhan keinginan user. Meliputi I/O, pengerjaan, ukuran dan jumlah data yang akan ditangani. Kedua, analysis, Analisa kebutuhan sistem dan software adalah proses menentukan arsitektur sistem secara total dan menentukan ukuran data dan jumlah data. 
Kemudian ketiga, design adalah menentukan dasar-dasar pembentukan dan pemilihan struktur data, struktur program, arsitektur program, pemilihan algoritma, intereksi dengan user. Selanjutnya coding adalah mentrasformasikan desain kedalam baris- baris program, pemilihan bahasa. Testing merupakan pengujian kebenaran program. Terakhir, maintenance adalah proses perawatan software agar dapat digunakan.

Langkah-langkah dalam pembuatan website yaitu pengumpulan kebutuhan user terhadap sistem yang akan dibuat dengan cara melakukan proses wawancara dan diskusi dengan mitra, pembuatan desain sistem dan basis data sesuai dengan kebutuhan system, implementasi desain sistem ke dalam bahasa pemrograman, menyiapkan server untuk tempat instalasi sistem dan uji coba sistem agar sesuai dengan kebutuhan mitra.

Adapun rincian tahapan digambarkan seperti berikut :

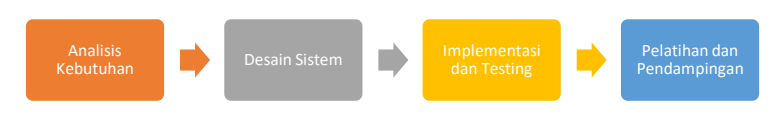

Gambar 2. Tahapan Pengabdian

\section{HASIL DAN PEMBAHASAN}

Hasil dan luaran yang dicapai dalam kegiatan penelitian ini dibagi menjadi dua, yaitu hasil perancangan website dengan luaran berupa produk website, dan hasil implementasi yang dirancang berupa website yang sudah dihosting dan dapat diakses oleh masyarakat luas.

\section{- Rancangan Website TK ABA 16 Malang}

Hasil rancang bangun sistem informasi website TK ABA 16 Malang dapat dilihat pada URL https://tkaba16malang.com. Tampilan homepage website dapat dilihat pada Gambar 3 dan Gambar 4. Gambar 3 merupakan hasil dari rancang bangun website sistem informasi yang menampilkan halaman utama untuk user dan pada Gambar 4 menampilkan halaman galeri untuk user.

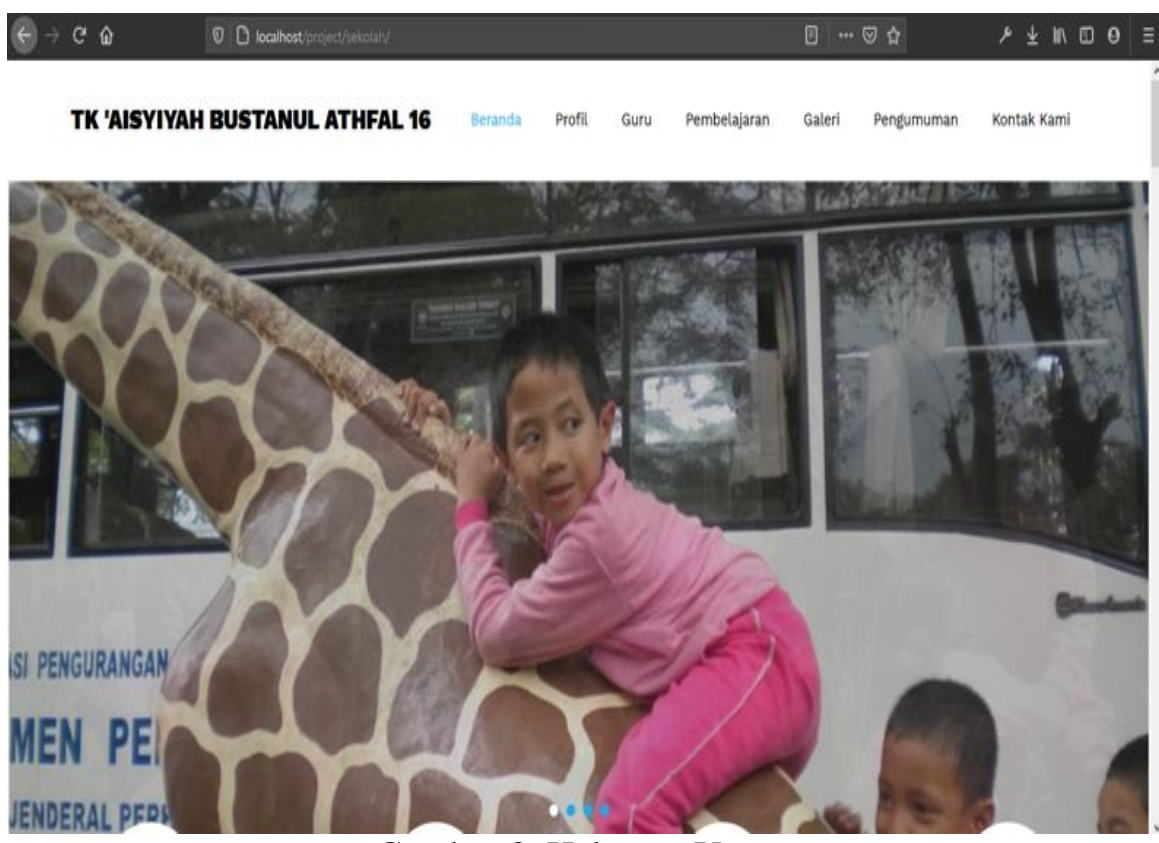

Gambar 3. Halaman Utama 

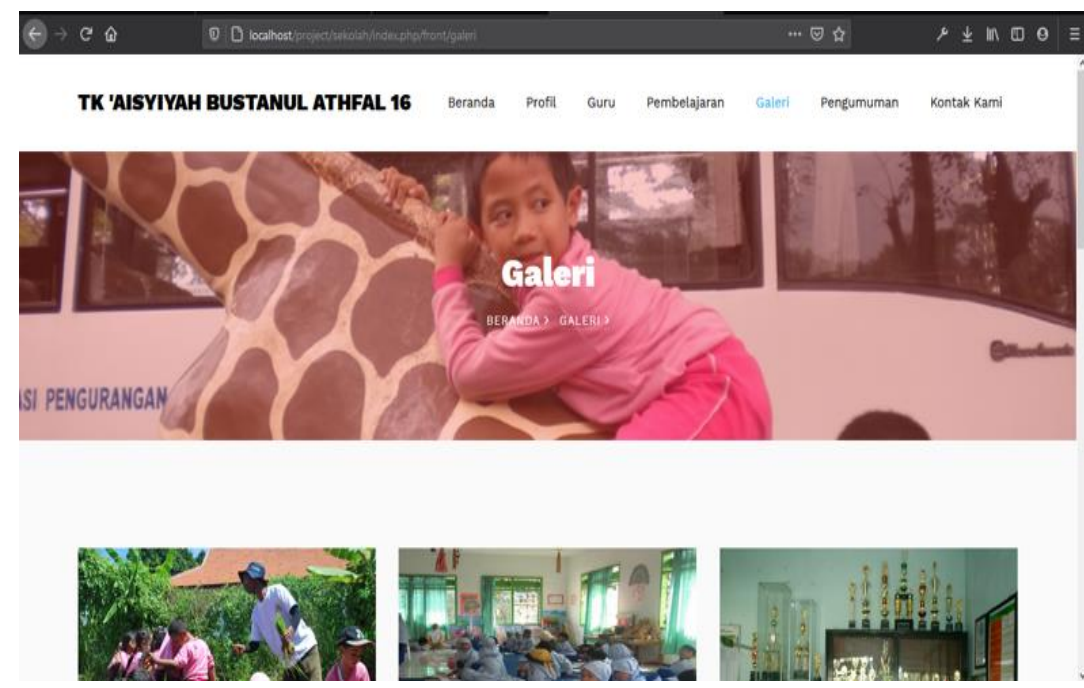

Gambar 5. Halaman Galeri

Pada Gambar 5 menunjukan halaman login untuk admin website dimana admin yang didaftarkan dapat berjumlah lebih dari 1 orang.

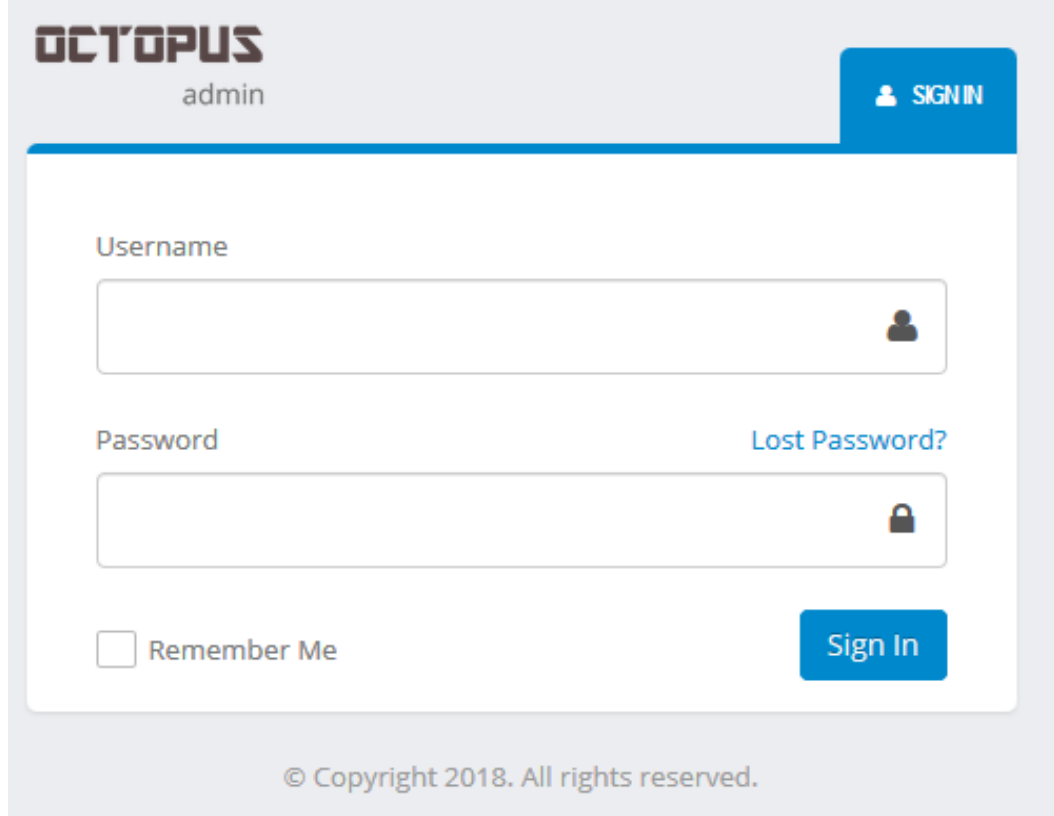

Gambar 5. Halaman Login Admin

Rancang bangun sistem informasi website TK ABA 16 Malang terdiri dari beberapa menu seperti dashboard, mailbox, data profil sekolah, data guru, data mata pelajaran, data pengumuman, data kontak sekolah, galeri dan user. Gambar 6 dan 7 merupakan hasil pembangunan sistem informasi pada halaman data profil sekolah. Setiap menu yang terdapat pada kategori Form memiliki 4 aksi yaitu CRUD (Create, Read, Update, Delete). Selain itu juga memiliki fitur pencarian dan penyortitan. 


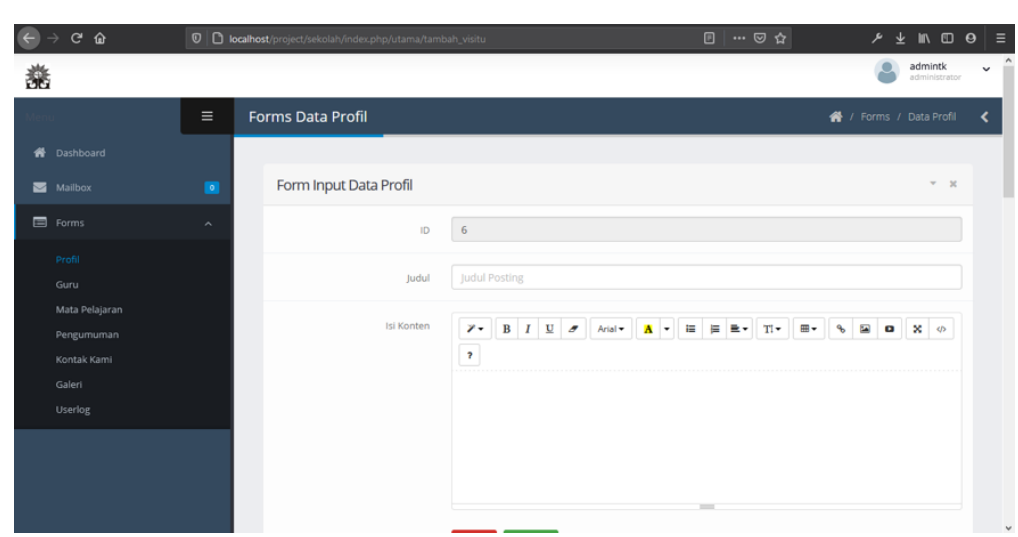

Gambar 6. Halaman Admin Input Data Profil Sekolah

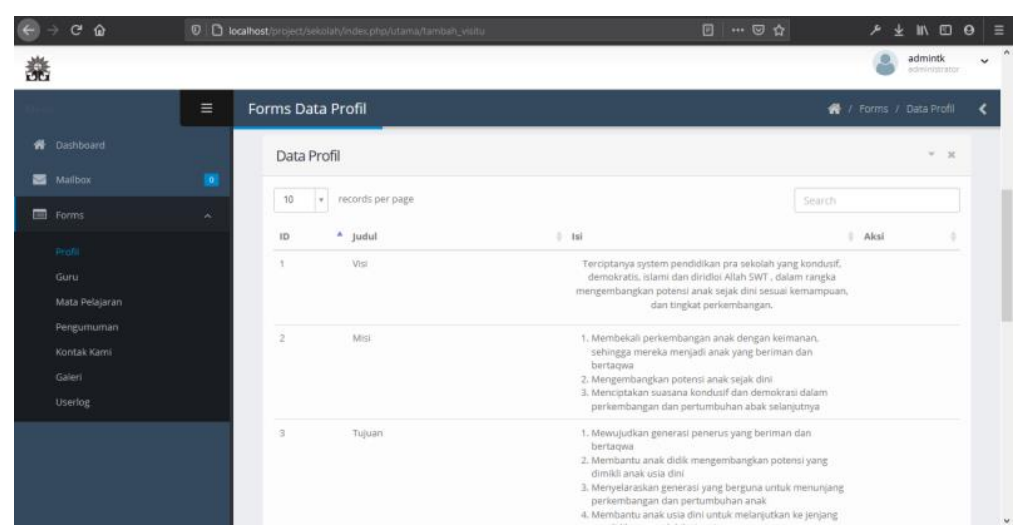

Gambar 7. Halaman Admin Data Profil Sekolah

Hasil rancang bangun pada Gambar 8 dan 9 menunjukan halaman mailbox atau pesan yang dikirim oleh user kepada admin. Dapat berisi pertanyaan seputar kegiatan sekolah atau lainnya.

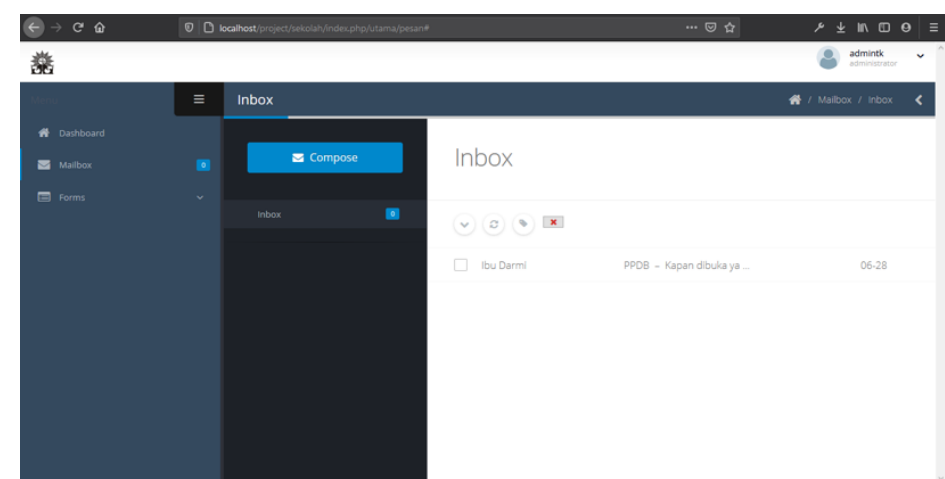

Gambar 8. Halaman Admin Mailbox Website TK ABA 16 Malang

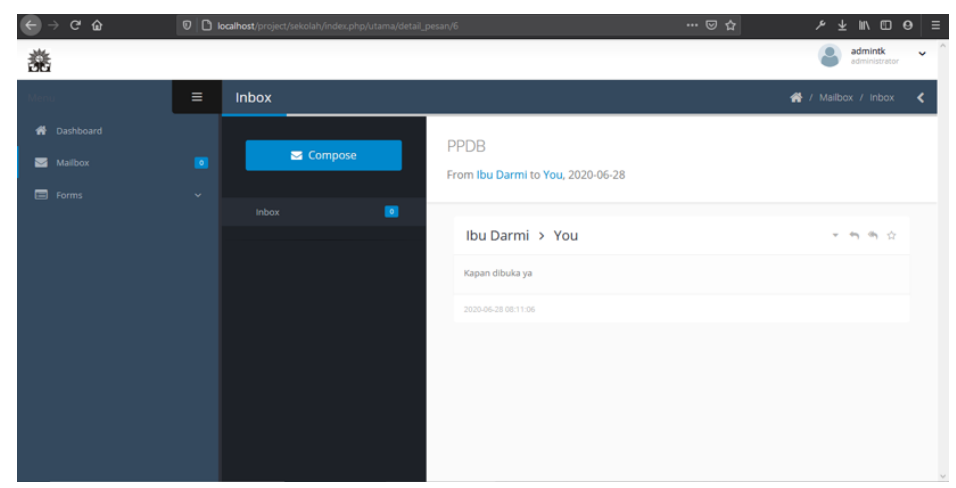

Gambar 9. Halaman Admin Detail Pesan 


\section{- Pelatihan Pengguna}

Website yang sudah dihosting dan dapat diakses oleh masyarakat luar, membutuhkan pemelihatan agar informasi yang ditampilkan dapat selalu terbaharui. Maka dari perlu dilakukan pelatihan yang diikuti oleh guru dan pengelola jurnal TK ABA 16 Malang. Pelatihan dilakukan selama satu hari penuh yaitu mulai jam 08.00 sampai dengan jam 16.00, bertempat di aula TK. Kegiatan pelatihan dapat dilihat seperti pada Gambar 10.

\section{SIMPULAN}

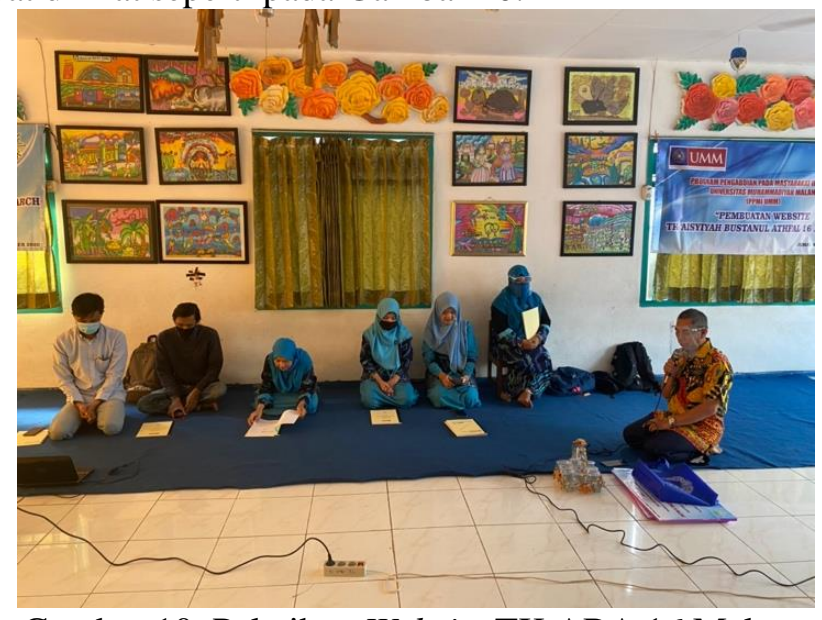

Gambar 10. Pelatihan Website TK ABA 16 Malang

Berdasarkan pembahasan di atas, kegiatan pengabdian kepada masyarakat ini mampu menyelesaikan permasalahan mitra yang belum memiliki fasilitas website dimana setiap terdapat informasi mengenai sekolah hanya ditampilkan di majalah dinding sekolah. Hasil yang dicapai dalam kegiatan pengabdian ini adalah pembuatan website TK ABA 16 Malang sehingga bisa dikenal oleh masyarakat luas untuk meningkatkan kualitas layanan sekolah.

\section{SARAN}

Perlu adanya pengembangan website terkait penambahan fitur pada website TK ABA 16 Malang tersebut agar lebih banyak informasi yang disampaikan kepada masyarakat.

\section{UCAPAN TERIMA KASIH}

Terimakasih kepada Direktorat Penelitian dan Pengabdian Kepada Masyarakat (DPPM) Universitas Muhammadiyah Malang atas dukungan terselenggaranya pekerjaan ini melalui skema Program Pengabdian Masyarakat Internal (PPMI) 2020.

\section{DAFTAR PUSTAKA}

Christian, A., Hesinto, S., \& Agustina, A. (2018). Rancang Bangun Website Sekolah Dengan Menggunakan Framework Bootstrap ( Studi Kasus SMP Negeri 6 Prabumulih ). Jurnal $\begin{array}{llllll}\text { Sisfokom (Sistem Informasi Dan } & \text { Komputer), } & 7(1), & 22 .\end{array}$ https://doi.org/10.32736/sisfokom.v7i1.278

Fauzi, F. (2019). Implementasi Manajemen Berbasis Sekolah (MBS) dalam Peningkatan Prestasi Belajar Siswa di SMP 10 Nopember Sidoarjo. Jurnal Tarbawi STAI Al Fithrah, 61-76.

Irawan, Y., Susanti, N., \& Triyanto, W. A. (2016). Analisa Dan Perancangan Sistem Informasi Sekolah Berbasis Website Untuk Penyampaian Informasi Sekolah Dan Media Promosi Kepada Masyarakat. Simetris : Jurnal Teknik Mesin, Elektro Dan Ilmu Komputer, 7(1), 257. https://doi.org/10.24176/simet.v7i1.512

Ramadhani, S., Anis, U., \& Masmuro, S. T. (2013). Rancang Bangun Sistem Informasi Geografis Layanan Kesehatan Di Kecamatan Lamongan Dengan PHP MySQL. Jurnal Teknika, 5(MYsql), 479-484. https://doi.org/10.1007/978-1-62703-471-5_1

Simanjorang, R. M., Hutahaean, H. D., \& Sihotang, H. T. (2017). Sistem Pendukung Keputusan Penentuan Penerima Bahan Pangan Bersubsidi Untuk Keluarga Miskin Dengan Metode AHP Pada Kantor Kelurahan Mangga. Journal Of Informatic Pelita Nusantara, 2(1), 22-31. http://e-jurnal.pelitanusantara.ac.id/index.php/JIPN/article/view/274/172 